\title{
Joseph und Aseneth
}

\author{
Hrsg. v. Eckart Reinmuth. Eingel., ed., übers. u. m. interpretierenden Essays \\ versehen v. Eckart Reinmuth, Stefan Alkier, Brigitte Boothe, Uta B. Fink, Christine \\ Gerber, Karl-Wilhelm Niebuhr u.a.
}

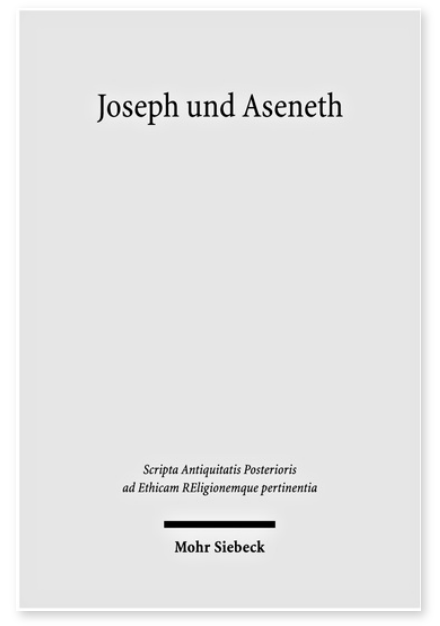

2009. XI, 280 Seiten. SAPERE XV

ISBN 978-3-16-156439-0

DOI 10.1628/978-3-16-156439-0

eBook PDF

ISBN 978-3-16-150162-3

Leinen $59,00 €$
Die Erzählung Joseph und Aseneth ist Liebes- und Bekehrungsgeschichte in einem. Sie berichtet von der stolzen ägyptischen Priestertochter Aseneth, ihrer Liebe zu Joseph, dem Sohn Jakobs, ihrer Bekehrung und Bewahrung, und knüpft damit an eine Notiz der biblischen Josephserzählung an (Gen 41,45). Dieses Erzählwerk des antiken Judentums wird in einer aktuellen Übersetzung auf neuester textkritischer Grundlage geboten. Die einführenden Beiträge lassen das weite Themenspektrum anklingen, das mit Joseph und Aseneth berührt wird. Neben den einleitungswissenschaftlichen und textkritischen Fragen stehen die rechts- und wirtschaftsgeschichtlichen Verhältnisse, der religionshistorische Hintergrund, die Bedeutung für das Neue Testament, Erzählstruktur und Ethik sowie psychologische Aspekte, aber auch die erstaunliche Wirkungsgeschichte dieser Erzählung im Mittelpunkt.

Eckart Reinmuth ist Professor für Neues Testament an der Universität Rostock.

Stefan Alkier Geboren 1961; Studium der Ev. Theologie, Germanistik und Philosophie in Münster, Bonn und Hamburg; 1993 Promotion; 1999 Habilitation; seit 2001 Professor für Neues Testament und Geschichte der Alten Kirche am Fachbereich Evangelische Theologie der Goethe-Universität Frankfurt am Main.

Brigitte Boothe ist Professorin für Klinische Psychologie an der Universität Zürich.

Uta Barbara Fink Keine aktuellen Daten verfügbar.

Christine Gerber Geboren 1963; Studium der Ev. Theologie; 1996 Promotion an der Ludwig-Maximilians-Universität München; 2005 Habilitation an der Humboldt-Universität zu Berlin; seit 2007 Professorin für Neues Testament am Fachbereich Evangelische Theologie der Universität Hamburg.

Karl-Wilhelm Niebuhr Geboren 1956; 1986 Promotion; 1991 Habilitation; 1994-96 Professor für Biblische Theologie (evangelisch) an der Technischen Universität Dresden; 1997-2022 Professor für Neues Testament an der Friedrich-SchillerUniversität Jena; Präsident des Eastern Europe Liaison Committee (EELC) der Studiorum Novi Testamenti Societas (SNTS). https://orcid.org/0000-0002-8850-7046

Angela Standhartinger Geboren 1964; Studium der Ev. Theologie in Frankfurt/Main, München und Heidelberg; Promotion und Habilitation in Frankfurt; Vikariat und Ordination; Gastaufenthalt am Union Theological Seminary in New York; seit 2000 Professorin für Neues Testament in Marburg.

Manuel Vogel ist Professor für Neues Testament an der Universität Jena.

Jürgen K. Zangenberg Studium der evangelischen Theologie in Erlangen, Heidelberg und Edinburgh; Promotion zum Dr theol. 1996 an der Ruprecht-Karls-Universität Heidelberg; 2003 Habilitation an der Kirchlichen Hochschule und der Bergischen Universität Wuppertal; seit 2006 Professor für Neues Testament und Frühchristliche Literatur sowie seit 2008 auch an der Fakultät für Archäologie der Universität Leiden/Niederlande. https://orcid.org/0000-0001-7894-3605

\section{Jetzt bestellen:}

https://mohrsiebeck.com/buch/joseph-und-aseneth-9783161564390?no cache=1

order@mohrsiebeck.com

Telefon: +49 (0)7071-923-17

Telefax: +49 (0)7071-51104 